\title{
RECUPERANDO, COMPARANDO E APRECIANDO BRICADEIRAS DE RUA DE DIFERENTES GERAÇÕES EM BAURU, SP: FORMAÇÃO DA IDENTIDADE E PADRÃO POR GENÊRO
}

Jorgeta Zogheib Milanezi

Aguinaldo Gonçalves

Carlos Roberto Padovani

\section{Resumo}

O presente projeto expressa como objetivos: i-) identificar jogos e brinquedos praticados nos anos 50 , em Bauru, SP, e qual o significado dos mesmos para aqueles que os vivenciaram; ii-) sistematizar como e quais são os da geração subseqüente e iii-) propor subsídios para as escolas preservarem a cultura local no que diz respeito a tais expressões. Os dados foram coletados a partir dos relatos de memória e de entrevistas com pessoas que, na década de 50, encontravam-se na faixa entre 08 e 13 anos e também com crianças entre 10 e 12 anos, da Escola Municipal de $1^{\circ}$ Grau Santa Maria, localizada no bairro Vila Cardia. Destas, analisaram-se 19 do gênero feminino e 20 do masculino, segundo a metodologia de Kosminsky (1984). Obtendo-se 127 referências de brincadeiras que não se repetiram entre as gerações, as comuns a ambas (53 e 60 respectivamente) foram submetidas a análise inferencial, pelo teste de Goodman. Inspeção imediata de tais resultados apontou para aparente associação entre brincadeiras e um padrão segundo gênero, aspecto a seguir também considerado e demonstrado pelas comparações intra e interpopulacionais multinominais, em relação aos postos mais freqüentemente referidos. Como resultado geral obtido, foi possível, não obstante as flutuações de freqüência observadas entre as ambas as gerações, constatar e discutir a consecução dos objetivos inicialmente postos, bem como a distribuição preferencial constatada.

\section{Palavras-Chaves:}

Jogos; Brincadeiras; Práticas Pedagógicas ; Educação Física; Gênero

\section{RECOVERING, COMPARING AND APPRECIATING STREET GAMES OF DIFFERENT GENERATIONS IN BAURU, SP: CONSTRUCTION OF IDENTITY AND PATTERN BY GENDER}

Jorgeta Zogheib Milanezi

Aguinaldo Gonçalves

Carlos Roberto Padovani

\begin{abstract}
This present study has as objectives: i-) the identification of games and plays developed on the 50's, in Bauru, SP and what is the meaning of said games for those who experienced them; ii-) systematize which and how are those of the ensuing generation; and iii-) propose subsidies for the schools to preserve the local culture as related to these expressions. Data was collected from memories reports and interviews with individuals who at the 50's were aged from 08 to 13, as well as with children aged 10 to 12 , from the Escola Municipal de $1^{\circ}$ Grau Santa Maria (Santa Maria Elementary School), located in Vila Cardia district. From them, 19 of the feminine gender and 20 of the masculine gender were analysed, following Kosminsky methodology. In an exploratory frequency distribution were obtained 127 references of plays that were not repeated between the generations; those which were common to both (53 and 60 respectively) were submitted to inference analysis under the Goodman test. The gender variable was also
\end{abstract}


considered when outlining multinominal comparisons intra and inter-populational, as related to the posts more frequently mentioned. As a general result obtained, it was possible notwithstanding the frequency fluctuations observed among both generations, determine the existence of association among the games and a pattern in accordance to gender.

\section{Key-Words:}

Game; Plays; Pedagogical Practices; Physical Education; Gender 


\section{Introdução}

Durante o início do século XX, através da conhecida "marcha do café" a região noroeste de São Paulo se tornou a franja de expansão para oeste do Estado e a cidade de Bauru foi sendo povoada. Em decorrência, as estradas de ferro vieram para o escoamento da produção regional. Esses elementos mostraram-se indutores do processo de urbanização. Temos, portanto, o café e as ferrovias Noroeste do Brasil, Companhia Paulista de Estradas de Ferro e a Estrada de Ferro Sorocabana a formar destacado entroncamento. Num segundo momento, o comércio passa a ser fator determinante para a expansão da rede urbana. Para Bastos (1994), após algumas décadas, pode-se concluir que Bauru apresenta-se como cidade de médio porte e com significativa relevância pela convergência viária próxima ao centro geográfico do Estado, passagem natural daqueles que se dirigem da capital rumo à Alta Paulista ou à Noroeste, em direção a Mato Grosso, Bolívia, Paraguai e Peru.

Segundo Vervier e Vieira (1991), no fim dos anos oitenta, Bauru já se torna pólo de alta densidade demográfica e, por esses motivos, especializada nas atividades terciárias de comércio e serviços. Seria ingênuo imaginar que com essas dimensões comerciais, industriais e de prestação de serviços, estivesse infensa à proliferação dos questões urbanas que afligem o país e todo o mundo, destacadamente a falta de lazer. No caso específico, o planejamento social ficou relegado a segundo plano. Só após o aparecimento de problemas é que se propuseram perspectivas a longo prazo com a elaboração de um Plano Diretor. As soluções oferecidas não impediram a perda dos espaços de recreação, o que acarretou a diminuição ou ausência de brincadeiras de rua, fato a refletir-se no desenvolvimento infantil, tanto a nível biológico como também psicossocial (MILANEZI, 1995). De fato, com o crescimento das cidades, as ruas foram asfaltadas, chegou a televisão, em seguido os microcomputadores; o desenvolvimento da indústria automobilística congestionou as ruas, agora com placas de sinalização, faixa de pedestre, "bocas de lobo" enfim, parece que a rua é do automóvel (YURGEL, 1983).

No marco desse quadro de referências, para apreender e incorporar o teor do mundo em que vivem, as crianças vivenciam a realidade com bombardeio socialmente assimétrico de informações. A fantasia, o brinquedo e suas concepções vêm sendo modelados pela comunicação e pela tecnologia. Vestem roupas de heróis repetindo gestos, palavras e outras imposições mediáticas. Os modelos pré-fabricados são a "trama entre brinquedo, mercado e ideologia que cerca a criança e a torna cativa em um passe de mágica" (DAMAZIO, 1991). O jogo é atividade que está sempre presente nas brincadeiras e, de acordo com 
Huizinga (1990), é mais antigo que a cultura, com lugares e tempos diferentes da vida comum, pois existe desde as sociedades primitivas. No seu interior, tudo é movimento, mudança, alternância, sucessão:

Carrinho de rolimã, bonecas de pano, casinhas de madeira, balões pipas ( ou papagaios), bonecos ou bichos feitos com trapos e enchimento... Quem de nós deixou de se envolver com esses e outros brinquedos? (OLIVEIRA, 1984).

Ora, lembrando Alves (1993) "só aprendemos aquelas coisas que nos dão prazer". Em outros termos, para a pedagogia da vida é preciso seduzir o aluno valorizando a espontaneidade criadora, com o ambiente dos jogos atuando como mola mestra e o professor não apenas com o saber técnico, mas também político. Praticados com maior freqüência por populares, incluindo uma faixa da classe média, os jogos infantis constituem importantes formas de manifestação lúdica, a ocorrer principalmente em ruas, quintais, terrenos baldios e em pátios escolares (MELLO, 1985).

Cabem, então, interrogantes como: Onde estão as brincadeiras das ruas de Bauru? Será que foram para a periferia da cidade? Sofreram transformações para se adaptar às novas conformações do espaço coletivo? Surgiram outras? Migraram para espaços como a escola, os parques, as praças e os clubes? Isto posto, o presente projeto expressa como objetivos:

i-) identificar jogos e brinquedos desenvolvidos nos anos 50, em Bauru, $\mathrm{SP}$, e qual o significado dos mesmos para aqueles que os vivenciaram;

ii-) sistematizar como e quais são os da geração subseqüente e

iii-) propor subsídios para as escolas preservarem a cultura local no que diz respeito a tais expressões.

\section{Metodologia}

Com intenção de recuperar elementos dos citados referentes à identidade das brincadeiras no contexto definido, investigou-se o lugar e o sentido das mesmas em diferentes gerações locais na busca de compreender suas alterações.

Os dados foram coletados a partir dos relatos de memória e de entrevistas com pessoas que, na década de 50, encontravam-se na faixa entre 08 e 13 anos e também com crianças entre 10 e 12 anos, da Escola Municipal de $1^{\circ}$ Grau Santa Maria, localizada no bairro Vila Cardia. Destas, analisaram-se 19 do gênero 
feminino e 20 do masculino, segundo a metodologia de Kosminsky (1984), que procede à descrição de: a) características da cidade, do bairro e da rua como condições materiais de viabilização; b) rotina de vida e dimensão do aspecto lúdico no cotidiano estudado, c) festas e comemorações - contribuição das tradições coletivas na formação das pessoas; d) vizinhança e grupos de convivências; e) significado da infância para os entrevistados.

Obtendo-se, numa distribuição freqüêncial exploratória, 127 referências de brincadeiras que não se repetiram entre as gerações, as comuns a ambas (53 e 60 respectivamente) foram, a seguir, submetidas a análise inferencial, pelo teste de Goodman (Goodman, 1964). Considerou-se também a variável gênero no delineamento para comparações intra e interpopulacionais multinominais, em relação aos postos mais freqüentemente referidos.

\section{Resultados}

\section{Aspectos Quantitativos}

A Tabela 1 apresenta as distribuições de freqüências específicas às décadas estudadas: em seu interior, observa-se desde pronto a maior extensão relativa dos tipos referentes ao primeiro período (28 comparativamente a 17), a indicar provável maior atividade motora. $\mathrm{O}$ mesmo procedimento é executado na Tabela 2, em termos de brincadeiras comuns a ambos os anos (50 e 80), complementando-se no plano inferencial, segundo sexos, com a Tabela 3. A partir dela, a Tabela 4, delimitando-se às brincadeiras mais referidas em ambas as gerações, explora e constata permanência de padrão segundo sexo, aparentemente resistente ao passar dos anos configurados na situação sob estudo. 
Tabela 1- Distribuição de freqüências de brincadeiras específicas, referidas segundo gerações, Bauru/S.P.

\begin{tabular}{|c|c|c|c|c|c|}
\hline \multirow{2}{*}{$\begin{array}{l}\text { Brincadeiras } \\
\text { referidas }\end{array}$} & \multicolumn{2}{|c|}{ Primeira Geração } & \multirow{2}{*}{$\begin{array}{l}\text { Brincadeiras } \\
\text { referidas }\end{array}$} & \multicolumn{2}{|c|}{ Segunda Geração } \\
\hline & Freq. abs. & Freq. rel.(\%) & & Freq. abs. & Freq. rel.(\%) \\
\hline 1- Bola de gude & 14 & 14,14 & 1- Vôlei & 8 & 28,57 \\
\hline 2- Pião & 13 & 13,13 & 2- Burro & 3 & 10,72 \\
\hline 3-Salva & 12 & 12,12 & 3- Jogar basquete & 2 & 7,15 \\
\hline 4- Pular corda & 7 & 7,07 & 4- Patins & 2 & 7,15 \\
\hline 5- Amarelinha & 5 & 5,06 & 5- Jogar baralho & 1 & 3,57 \\
\hline 6- Nadar no rio & 4 & 4,04 & 6- Estrela nova & 1 & 3,57 \\
\hline 7- Garrafão & 4 & 4,04 & 7- Duro ou mole & 1 & 3,57 \\
\hline 8-Patinete & 3 & 3,03 & 8- Pega gelinho & 1 & 3,57 \\
\hline 9- Carrinho rolimã & 3 & 3,03 & 9- Salada mista & 1 & 3,57 \\
\hline 10- Ordem & 3 & 3,03 & $\begin{array}{l}\text { 10- Apertar } \\
\text { campainha }\end{array}$ & 1 & 3,57 \\
\hline 11-Pique & 3 & 3,03 & 11- Escalar & 1 & 3,57 \\
\hline 12- Médico & 3 & 3,03 & 12- Quarto escuro & 1 & 3,57 \\
\hline 13-Peteca & 3 & 3,03 & $\begin{array}{l}\text { 13- Elefante } \\
\text { colorido }\end{array}$ & 1 & 3,57 \\
\hline 14- Circo & 2 & 2,02 & 14- Queima parede & 1 & 3,57 \\
\hline 15- Cantiga de roda & 2 & 2,02 & 15- Gato mia & 1 & 3,57 \\
\hline $\begin{array}{l}\text { 16- Jogo de } \\
\text { saquinho }\end{array}$ & 2 & 2,02 & 16- Gol a gol & 1 & 3,57 \\
\hline 17- Bola atrás & 2 & 2,02 & 17- Discoteca & 1 & 3,57 \\
\hline 18- Passa anel & 2 & 2,02 & & & \\
\hline 18- Pular sela & 2 & 2,02 & & & \\
\hline 20- Bilboquê & 2 & 2,02 & & & \\
\hline $\begin{array}{l}21 \text { - Mocinho e } \\
\text { bandido }\end{array}$ & 1 & 1,01 & & & \\
\hline 22- Barra manteiga & 1 & 1,01 & & & \\
\hline 23- Passa cavaleiro & 1 & 1,01 & & & \\
\hline 24- Gato e rato & 1 & 1,01 & & & \\
\hline $\begin{array}{l}\text { 25- Faça o que o } \\
\text { mestre mandar }\end{array}$ & 1 & 1,01 & & & \\
\hline 26- Arco no chão & 1 & 1,01 & & & \\
\hline 27- Cabo de guerra & 1 & 1,01 & & & \\
\hline 28- Unha na mula & 1 & 1,01 & & & \\
\hline Total & 99 & 100,00 & Total & 28 & 100,00 \\
\hline
\end{tabular}


Tabela 2- Distribuição de freqüências de brincadeiras comuns referidas, segundo gerações, Bauru/ S.P.

\begin{tabular}{|c|c|c|c|c|}
\hline \multirow{3}{*}{ Brincadeiras referidas } & \multicolumn{4}{|c|}{ Geração } \\
\hline & \multicolumn{2}{|c|}{ Primeira } & \multicolumn{2}{|c|}{ Segunda } \\
\hline & Freq. abs. & Freq. rel.(\%) & Freq. abs. & Freq. rel.(\%) \\
\hline Futebol & 9 & 16,98 & 3 & 5,00 \\
\hline Esconde-esconde & 7 & 13,21 & 19 & 31,66 \\
\hline Empinar papagaio (Pipa) & 7 & 13,21 & 2 & 3,33 \\
\hline Pega-pega & 5 & 9,43 & 14 & 23,33 \\
\hline Casinha & 4 & 7,55 & 1 & 1,67 \\
\hline Jogar bola & 4 & 7,55 & 4 & 6,67 \\
\hline Bete & 3 & 5,66 & 3 & 5.00 \\
\hline Bicicleta & 3 & 5,66 & 2 & 3,33 \\
\hline Queima & 3 & 5,66 & 3 & 5,00 \\
\hline Balança caixão & 3 & 5,66 & 1 & 1,67 \\
\hline Cobra cega & 2 & 3,77 & 1 & 1,67 \\
\hline Pé na lata & 2 & 3,77 & 4 & 6,67 \\
\hline Mamãe da rua & 1 & 1,89 & 3 & 5,00 \\
\hline Total & 53 & 100,00 & 60 & 100,00 \\
\hline
\end{tabular}

Tabela 3 - Proporção de brincadeiras referidas comuns às gerações sucessivas, na cidade de Bauru/SP.

\begin{tabular}{l|c|c|c|ccc}
\hline \multirow{2}{*}{ Brincadeiras } & \multicolumn{3}{|c|}{ Primeira Geração } & \multicolumn{3}{c}{ Segunda Geração } \\
\cline { 2 - 7 } & Masc. & Fem. & Ambos & Masc. & Fem. & Ambos \\
\hline Futebol & $0,57 \mathrm{~b}$ & $0,17 \mathrm{a}$ & $0,45 \mathrm{~B}$ & $0,15 \mathrm{a}$ & $0,00 \mathrm{a}$ & $0,08 \mathrm{~A}$ \\
Pega-pega & $0,21 \mathrm{a}$ & $0,33 \mathrm{a}$ & $0,25 \mathrm{~A}$ & $0,25 \mathrm{a}$ & $0,26 \mathrm{a}$ & $0,26 \mathrm{~A}$ \\
Bete & $0,14 \mathrm{a}$ & $0,00 \mathrm{a}$ & $0,10 \mathrm{~A}$ & $0,20 \mathrm{a}$ & $0,00 \mathrm{a}$ & $0,10 \mathrm{~A}$ \\
Bicicleta & $0,00 \mathrm{a}$ & $0,50 \mathrm{~b}$ & $0,15 \mathrm{~A}$ & $0,05 \mathrm{a}$ & $0,05 \mathrm{a}$ & $0,05 \mathrm{~A}$ \\
Esconde-esconde & $0,36 \mathrm{a}$ & $0,33 \mathrm{a}$ & $0,35 \mathrm{~A}$ & $0,55 \mathrm{a}$ & $0,47 \mathrm{a}$ & $0,51 \mathrm{~A}$ \\
Cobra cega & $0,00 \mathrm{a}$ & $0,33 \mathrm{~b}$ & $0,10 \mathrm{~A}$ & $0,00 \mathrm{a}$ & $0,05 \mathrm{a}$ & $0,03 \mathrm{~A}$ \\
Casinha & $0,00 \mathrm{a}$ & $0,50 \mathrm{~b}$ & $0,15 \mathrm{~A}$ & $0,00 \mathrm{a}$ & $0,05 \mathrm{a}$ & $0,03 \mathrm{~A}$ \\
Pipa & $0,29 \mathrm{~b}$ & $0,00 \mathrm{a}$ & $0,20 \mathrm{~A}$ & $0,05 \mathrm{a}$ & $0,00 \mathrm{a}$ & $0,03 \mathrm{~A}$ \\
Pé na lata & $0,14 \mathrm{a}$ & $0,00 \mathrm{a}$ & $0,10 \mathrm{~A}$ & $0,20 \mathrm{a}$ & $0,00 \mathrm{a}$ & $0,10 \mathrm{~A}$ \\
Queima & $0,07 \mathrm{a}$ & $0,33 \mathrm{~b}$ & $0,15 \mathrm{~A}$ & $0,00 \mathrm{a}$ & $0,16 \mathrm{a}$ & $0,08 \mathrm{~A}$ \\
Balança caixão & $0,14 \mathrm{a}$ & $0,00 \mathrm{a}$ & $0,10 \mathrm{~A}$ & $0,00 \mathrm{a}$ & $0,05 \mathrm{a}$ & $0,03 \mathrm{~A}$ \\
Jogar bola & $0,14 \mathrm{a}$ & $0,00 \mathrm{a}$ & $0,10 \mathrm{~A}$ & $0,15 \mathrm{a}$ & $0,05 \mathrm{a}$ & $0,10 \mathrm{~A}$ \\
Mamãe da rua & $0,00 \mathrm{a}$ & $0,00 \mathrm{a}$ & $0,10 \mathrm{~A}$ & $0,05 \mathrm{a}$ & $0,11 \mathrm{a}$ & $0,08 \mathrm{~A}$ \\
\end{tabular}

Obs. 1) letras minúsculas: comparação de sexo dentro da década;

2) letras maiúsculas: comparação das décadas, considerando o total de respostas. 
Tabela 4 - Proporção, entre sexos, de brincadeiras mais freqüentemente referidas.

\begin{tabular}{lr|r}
\hline Brincadeiras & Masculino & \multicolumn{1}{|l}{ Feminino } \\
Primeira Geração & & \\
& & \\
Salva & $0,57 \mathrm{a}$ & $0,67 \mathrm{a}$ \\
Pular corda & $0,07 \mathrm{a}$ & $1,00 \mathrm{~b}$ \\
Pião & $0,64 \mathrm{a}$ & $0,67 \mathrm{a}$ \\
Amarelinha & $0,00 \mathrm{a}$ & $0,83 \mathrm{~b}$ \\
Bola de gude & $0,86 \mathrm{~b}$ & $0,33 \mathrm{a}$ \\
Segunda Geração & & \\
& & \\
Vôlei & $0,00 \mathrm{a}$ & $0,42 \mathrm{~b}$ \\
Burro & $0,05 \mathrm{a}$ & $0,11 \mathrm{a}$ \\
Basquete & $0,05 \mathrm{a}$ & $0,05 \mathrm{a}$ \\
Patins & $0,00 \mathrm{a}$ & $0,11 \mathrm{a}$ \\
& & \\
\hline
\end{tabular}

\section{Aspectos Qualitativos}

Os relatos fazem do pesquisador, "ouvinte" de muitos narradores, facilitando trabalho centrado no resgate e transmissão de experiências, o que proporciona "iluminação" do presente. Trazem, muitas vezes, visões particulares de acontecimentos; ao mesmo tempo são ricos no que diz respeito a retratar o viver e os costumes, sendo fundamental para o entendimento do "ambiente" da época.

Se a importância da memória está no fato de que nos possibilita colocarmo-nos como destinatários de uma herança cultural e de um passado que pode ter muito a nos dizer, a busca da infância nesses relatos se inscreve nesse contexto (SILVIA; GARCIA; FERRARI, 1989).

Ao ler as entrevistas, nota-se que o destaque conferido a esse período da vida é grande e que a vivência adquirida no mesmo foi de certa forma determinante.

Minha infância foi maravilhosa e repleta de brincadeiras sadias e criativas que até hoje estão presentes em minha vida e sempre contribuíram para o meu crescimento físico, mental, espiritual e emocional. (entrevista da primeira geração )

Declarações como essa, além de estarem vivas como momentos felizes, demonstram que as brincadeiras enriqueceram em muitos sentidos a vida de quem depõe. 
A Praça Rui Barbosa era acolhedora e as belas árvores mantinham sombra constante, convidando os transeuntes a pararem um pouco para se refrescarem do calor que sempre foi forte em Bauru e se deleitarem com a brisa. As águas passavam por baixo das pontes, com os animais (jacarés, patos e peixes) separados em espécie em pequenas piscinas. (entrevista da primeira geração)

Nota-se ainda, o saudosismo pela natureza que na década de 50 era mais facilmente acessível às crianças; os quintais muitas vezes continham pomares e animais proporcionando outras formas de contato. “Aprendi a andar a cavalo no sítio e brincava no rio Batalha." (entrevista da primeira geração)

E pode-se relevar o benefício desse contato para as crianças, que aprenderam a valorizá-la, tanto que aparece como marcante na trajetória de cada um. Memória e experiência têm relação estreita, já que muitas vezes não se referem unicamente ao fato, mas também àquilo que foi vivido por alguém e que pode ser transmitido para outros por dizer respeito a eles também. Com efeito, se a experiência se enfraquece, deixa aos indivíduos o predomínio da vivência imediata, o que acaba por obstaculizar vínculos com o passado e com a tradição.

"Essas brincadeiras não são importantes para minha vida porque elas me levam a lugar nenhum" (entrevista da segunda geração)

É inegável que, conseqüentemente, há a perda de todo o processo de identidade do "self”.

“As brincadeiras são importantes, porque essas brincadeiras passam de pai para filho." (entrevista da segunda geração)

Algumas das brincadeiras realizadas naquela época são executadas atualmente em menor proporção; vale dizer que não houve ruptura total com o passado e que a relação de semelhança permitirá noção mais exata de onde estamos e para onde nos direcionaremos. Essa geração dos anos 50 contava com maior liberdade no que diz respeito a espaço físico, e, por não possuir opções a nível pessoal muito diversificadas, era aí que realmente encontrava diversão.

\section{Comentários}

Seria difícil avaliar hoje, as influências ocorridas com os entrevistados da década de 50 sobre o desenvolvimento psicomotor, cognitivo e social; porém, se perquirirmos os efeitos psicológicos expressados de maneira empírica, verificamos valiosa contribuição: os participantes atribuem-lhes a aquisição de valores como socialização, solidariedade, auto-conhecimento e alteridade, o exercício da 
criatividade, a representação de modelos e o respeito mútuo. Com base nos resultados da pesquisa, recomenda-se incentivar intencional e planejadamente as brincadeiras no interior das práticas pedagógicas da Educação Física $(\mathrm{EF})$ visando a contribuir para atender às necessidades e interesses da idade, além de possibilitar a preservação de valores culturais. Quando nos referimos à presença do lúdico, lembramos da realidade em que ele praticamente inexiste ou, quando existe, é tido como " tapa buracos", sendo relegado ao professor de EF a função de "chefe" dessa "brincadeira". E assim continua ele, através de inúmeras técnicas, a promover a interdisciplinaridade com pensamento lógico, criatividade, noções temporais e espaciais.

O elemento essencial da atividade lúdica é sua magia, onde tudo pode representar-se para a criança sem nenhum outro limite que o da sua imaginação e a consistência material de alguns objetos transformados em brinquedos" (DINELLO, 1985).

Atravessando todos esses aspectos de formação de identidade e de implicações para a EF, o estudo empreendido indica quantitativamente também que avulta a permanência de padrão de brincadeiras socialmente construído segundo gênero que resiste às mudanças ao longo do tempo, destacadamente históricas, sociais e tecnológicas, matizado pelas seguintes singularidades registradas:

1- Resgatou-se a lembrança de brincadeiras da primeira geração, como amarelinha, bola de gude (búrica), peteca, pião, salva, pula corda, entre outras, que exigiam atividade motora mais intensa, enquanto hoje as crianças se envolvem intensamente à frente da televisão desenvolvendo movimentos reflexos. (Tabela 1 e 2);

2- Observa-se, na comparação conjunta entre as gerações, que na primeira houve distribuições diferenciais para os gêneros: meninos com futebol e pipa e meninas com bicicleta, cabra cega, casinha e queima. (Tabela 3);

3- Na comparação de ambas as gerações, o futebol revelou diferença estatisticamente significativa. (Tabela 3);

4- No interior da primeira geração, das cinco mais freqüentemente referidas bola de gude é tipicamente masculina, enquanto pular corda e amarelinha são especificamente femininas. 
No interior da segunda geração, das quatros mais frequentemente relacionadas, continua presente a categorização por gênero: o vôlei é das meninas ( Tabela 4);

5- Em síntese, portanto, não obstante as flutuações de freqüência observadas entre as ambas as gerações, é possível vincar a existência de associação entre as brincadeiras e um padrão segundo gênero.

\section{Referências}

ALVES, R. Educação \& prazer. São Paulo: Dois Pontos, 1993.

BASTOS, I. A ocupação natural, jurisdicional e religiosa do sertão de Bauru. 1994. Dissertação (Mestrado) - Universidade Estadual Paulista, Bauru, 1994.

DAMAZIO, R. L. O que é criança. 2. ed. São Paulo: Brasiliense, 1991.

GOODMAN, L. A. Simultaneous confidence intervals for contrasts among multinominal populations. Annals of Mathematical Statistics, v. 35, n. 2, p. 716-25, 1964.

HUIZINGA, J. Homo ludens. 2. ed. São Paulo: Perspectiva, 1990.

KOSMINSKY, E. Pesquisas qualitativas: a utilização da técnica de história de vida e de depoimentos pessoais em sociologia. São Paulo: Centro de Estudos Rurais e Urbanos, 1984.

MELlO, A. M. Jogos populares infantis como recurso pedagógico da educação física escolar de $1^{\circ}$ grau no Brasil. 1994. Dissertação (Mestrado em Educação Física e Desportos) - Universidade Federal do Rio de Janeiro, 1985.

MILANEZI, J. Z. A ocupação espontânea dos espaços públicos de lazer - a quadra poliesportiva do Jardim Bela Vista/Bauru-SP: estudo de caso. 1995. Dissertação (Mestrado) - Universidade Estadual Paulista, Bauru, 1995.

OLIVEIRA, P. S. O que é brinquedo. São Paulo: Brasiliense, 1984.

SILVA, M. A. S. S., GARCIA, M. A. L; FERRARI, S. C. M. Memória e brincadeiras na Cidade de São Paulo nas primeiras décadas do Século XX. São Paulo: Cortez, 19983.

VERVIER J. H. VIEIRA, G. Bauru na década de 80: indicadores econômicos de curto prazo. Bauru: Mimeses, 1991.

YURGEL, M. Urbanismo e lazer. São Paulo: Nobel, 1983. 


\section{Jorgeta Zogheib Milanezi}

Faculdade de Educação Física/UNICAMP

Grupo de Saúde Coletiva, Epidemiologia e Atividade Física

\section{Aguinaldo Gonçalves}

Faculdade de Educação Física/UNICAMP

Grupo de Saúde Coletiva, Epidemiologia e Atividade Física

\section{Carlos Roberto Padovani}

Faculdade de Educação Física/UNICAMP

Grupo de Saúde Coletiva, Epidemiologia e Atividade Física 